\title{
A tribute to Rolf Neeb (1929-2006) on the 80th anniversary of his birth
}

\author{
Fritz Scholz
}

Published online: 2 May 2009

(C) Springer-Verlag 2009

The year 2009 marks the 80th anniversary of the birth of the eminent German analytical chemist Rolf Neeb (Fig. 1). Sadly, Rolf Neeb passed away 3 years ago; however, the 80th anniversary of his birth is an appropriate occasion to remember his many scientific achievements, especially his contributions to electroanalytical chemistry.

Rolf Neeb was born on January 7, 1929, in Mainz, the only child of the merchant Arthur Neeb and his wife Anna, née Lerch. In Mainz he went to the Leibnitz-Volksschule from 1935 to 1939 , and then until 1945 to the GutenbergOberrealschule. The war forced the Neeb family to leave Mainz and to settle temporarily in the village of Nierstein. However, Rolf Neeb was able to attend the Gymnasium (grammar school) in the nearby town of Oppenheim, and left with his Abitur (German school-leaving certificate) in 1948. In the same year he began to study chemistry at the reopened Johannes Gutenberg University in Mainz, where his teachers were W. Geilmann, F. Strassmann, T. Wieland, L. Horner, and G.V. Schulz. Neeb was a student with very wide interests, and even started to learn Arabic (personal information from T. Steudel). He finished his studies with a diploma, which was achieved under the guidance of the well-known analytical chemist Wilhelm Geilmann (May 16, 1891 to May 24, 1967) [1, 2]. Geilmann had been taught by Otto Wallach, Gustav Tammann, Richard Zsigmondy [3], and Carl Mannich [4, 5], and Mannich had supervised Geilmann's PhD work in Hannover. Thus, one can trace Rolf Neeb's scientific genealogy back in a

F. Scholz $(\bowtie)$

Institut für Biochemie, Universität Greifswald,

Felix-Hausdorff-Str. 4,

17487 Greifswald, Germany

e-mail: fscholz@uni-greifswald.de

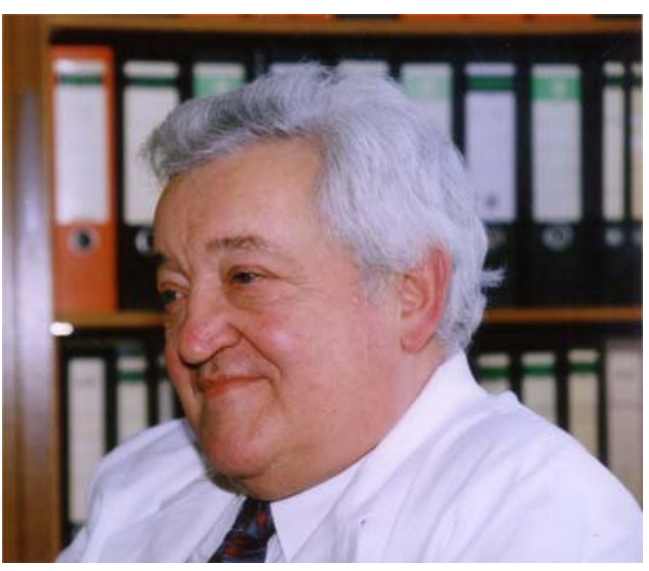

Fig. 1 Rolf Neeb in his office at Johannes Gutenberg University, Mainz. (Courtesy of Brigitte Neeb)

straight line to the great Johann Wolfgang Döbereiner [6], who was largely self-taught (see Fig. 2). The German writer and poet Johann Wolfgang von Goethe frequently consulted Döbereiner on chemical issues, and he strongly supported his work at Jena [7].

Rolf Neeb's diploma thesis (1954) concerned the separation of zinc from complex matrices. To achieve this he used a stream of hydrogen gas to reductively evaporate zinc metal-together with other reducible metals - and deposit them onto the cold parts of a quartz capillary. From there it was comparatively straightforward to dissolve the zinc in acid, and then determine the concentration using spectrophotometry or polarography [8, 9]. This was an early example of his scientific creativity, since we know that it was Neeb's idea to develop such a method, not that of his supervisor (personal information from T. Steudel). Neeb stayed in Geilmann's group and completed his $\mathrm{PhD}$ 
thesis within 2 years. This was granted summa cum laude. The topic of his PhD work was the analytical separation and determination of platinum, iridium, osmium, and rhenium [10-15]. Not only the short time in which his $\mathrm{PhD}$ was completed, but also the many papers that resulted from his research bear ample witness to Neeb's hardworking and original research style. Astonishingly, despite the short time available, and despite the absence of modern instrumental methods, many analyses were performed using classical techniques - separations by distillation or extraction, purifications by precipitation, and determinations by spectrophotometry and gravimetry. By 1959 he was able to submit his Habilitation (postdoctoral lecturing qualification) thesis to qualify for a professorship. In that work, Neeb turned his attention to modern instrumental techniques of analytical chemistry, as reflected in the title "Studies on the application of voltammetric and infrared spectroscopic methods for the enhancement of sensitivity and speed of inorganic-analytical determinations." The Habilitation work shows Neeb concentrating more and more on instrumental methods. Although some polarography had found its way into his diploma thesis, it was only after his $\mathrm{PhD}$ work had been completed that electroanalysis became the center of his attention, stimulated by his love of electronics.
Before discussing his contributions to electroanalysis in more detail, his career advancement may be noted. From 1959 to 1965 he was Privatdozent (lecturer), from 1965 to 1971 außerplanmäßiger Professor (associate professor), and in 1978 he became C3-Professor. Throughout his life Neeb hosted many foreign scholars in his laboratory, and his diploma and $\mathrm{PhD}$ students all became highly respected scientists in institutes and industry.

After 1959 Neeb published several seminal papers on the development and application of stripping voltammetry (e.g., [16-18]). Indeed, the varieties of stripping voltammetry remained central to Neeb's work for the rest of his life. There is hardly any other scientist who has advanced this topic in such a far-reaching way. His papers on stripping techniques are a tremendous resource for anybody working in this area. For example, Neeb developed intermodulation polarography [19-23], which is a kind of AC polarography where two sinusoidal $\mathrm{AC}$ voltages of slightly different frequencies are superimposed on a DC ramp and the current is measured at the combination frequency [24]. That component has only a small contribution from the background capacitance, because the latter responds only linearly to the perturbation, whereas faradaic processes respond nonlinearly. In his later papers, Neeb called this Doppeltonpolarographie ("double tone

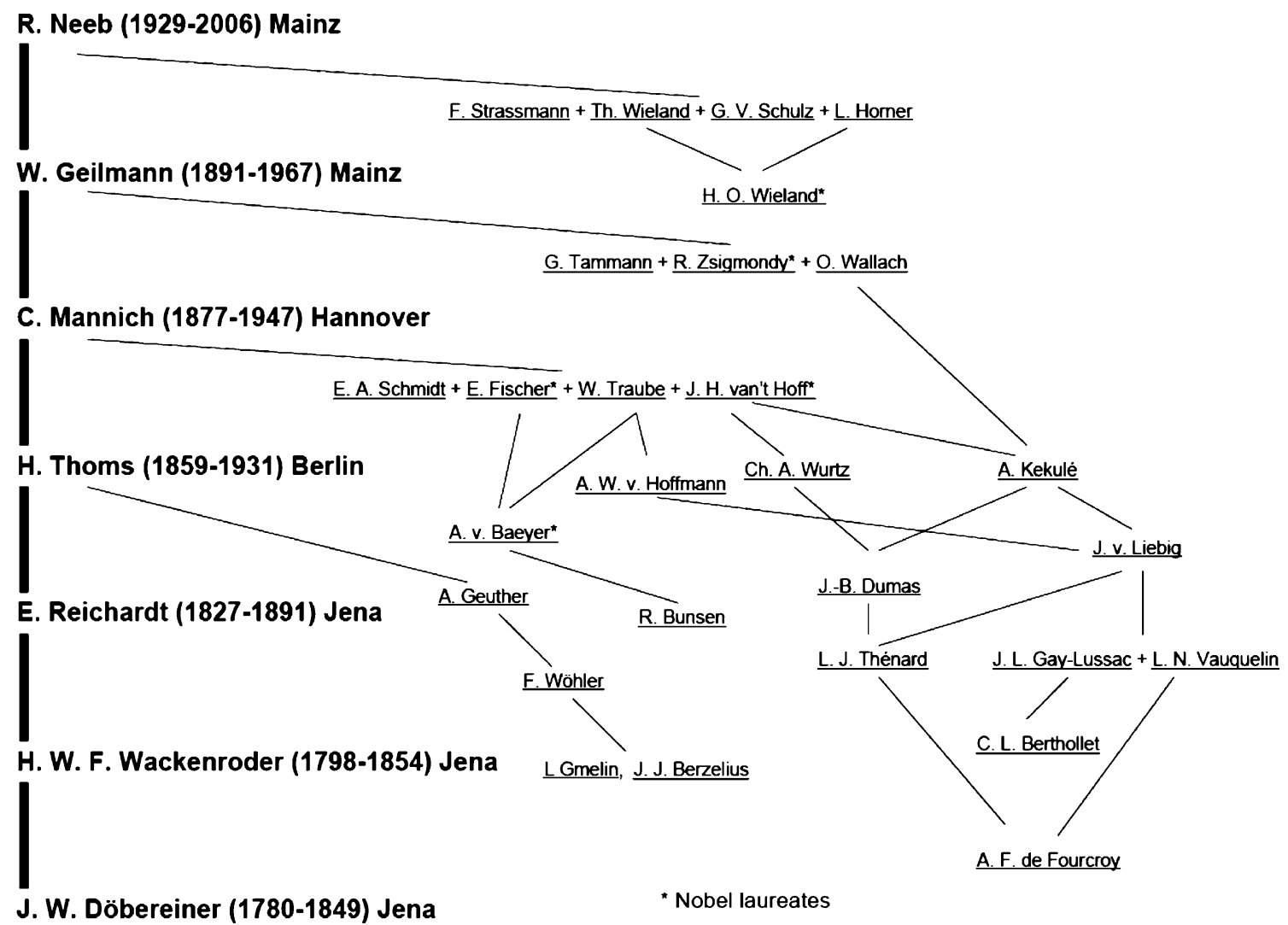

Fig. 2 Scientific genealogy of Rolf Neeb 
polarography") because of the use of two frequencies. Neeb also explored the analytical potential of intermodulation polarography both for faradaic reactions as well as for socalled tensammetric signals, i.e., adsorption-desorption signals due to strong changes of the differential double layer capacity, coupled to these signals. In [21] he described a filter that blocks the fundamental AC current frequency while allowing all higher harmonics to pass, which yields a significant increase in the sensitivity of stripping determinations. This led to much work on the improvement of the sensitivity of AC polarographic and voltammetric techniques by exploiting the presence of higher harmonics [23, 25], and he also published on the automation and synchronization of polarographic techniques [26, 27]. It is impossible to discuss here all his achievements in detail, but the general features of his research style are clear: he focused on electroanalysis, especially the stripping techniques; he had a masterly command of electronics, which allowed him to develop novel instrumentation highly suited to a given task; and he performed experiments with great rigor. Despite these disciplined and difficult methods, he nevertheless was able to publish an immense amount of data, which bears testimony to the extraordinary intensity with which he must have worked! In many cases, he was the sole author of the work.

Neeb contributed scholarly chapters on electroanalysis to various book publications, most notably the German Brockhaus (a general encyclopedia). His opus magnum was the book Inverse Polarographie und Voltammetrie [28], in which he summarized the theoretical basis of stripping voltammetry, and also described numerous analytical methods. Sadly, this book has never been translated into English. In his later years Neeb also used differential pulse voltammetry and potentiometric stripping for various analytical applications. He also published numerous meticulously elaborated determinations of metal ions, and a monograph on electrochemical analysis [29]. In addition to his electroanalytical research, he also developed several gas-chromatographic determinations of metals utilizing volatile metal complexes (e.g., [30]).

Rolf Neeb passed away on March 18, 2006 in Mainz, leaving his wife Brigitte and their three sons. As regards his personality, others are more competent to write than I, as I met him only once (on the occasion of a visit to Mainz in 1990) but I encountered an amiable, even-tempered, and very friendly character. On the occasion of his 60th birthday in 1989, his coworkers prepared a formidable book ${ }^{1}$ with all his journal publications, a preface written by
Rudolf Bock, a CV written by $\mathrm{H}$. Eschauer, personal memories written by T. Steudel, and a collection of photos. Only a few copies of that book now exist, but it bears witness to the enduring respect and love his coworkers felt for their old mentor. Yet Neeb's passing went almost unnoticed by the wider scientific community. It is therefore a particular pleasure to rectify this omission, and commemorate the 80th anniversary of the birth of this unassuming and humble man, who contributed so much to the science of electrochemistry.

Acknowledgements I am very thankful to T. Steudel, D. Saur, and G. Tölg for providing most helpful personal information, and I would like to thank Stephen Fletcher, Loughborough, for his suggestions to improve this text.

\section{References}

1. Bode H, Strassmann F (1951) Fresenius Z Anal Chem 133:1

2. Bode H (1966) Fresenius Z Anal Chem 166:1

3. Scholz F (2008) In: Bard AJ, Inzelt G, Scholz F (eds) Electrochemical dictionary. Springer, Berlin, p 723

4. Friedrich C, Dallmann C (1991) Pharm Z 136:691

5. Scholz F (2008) Pharmazie 63:916

6. Kauffman GB (1999) Platinum Metals Rev 43:122

7. Schwedt (1998) Goethe als Chemiker. Springer, Berlin

8. Geilmann W, Neeb R (1954) Z Pflanzenernahr Dung Bodenkd 67:38

9. Geilmann W, Neeb R (1955) Angew Chem 67:26

10. Geilmann W, Neeb R (1956) Fresenius Z Anal Chem 152:96

11. Neeb R (1956) Fresenius Z Anal Chem 152:158

12. Neeb R (1957) Fresenius $Z$ Anal Chem 154:17

13. Neeb R (1957) Fresenius Z Anal Chem 154:23

14. Geilmann W, Neeb R (1957) Fresenius Z Anal Chem 156:411

15. Geilmann W, Neeb R (1957) Fresenius Z Anal Chem 156:420

16. Neeb R (1959) Fresenius $Z$ Anal Chem 171:321

17. Neeb R (1961) Fresenius Z Anal Chem 180:161

18. Neeb R (1962) Angew Chem 74:203

19. Neeb R (1962) Naturwissenschaften 49:447

20. Neeb R (1965) Fresenius Z Anal Chem 208:168

21. Neeb R (1966) Fresenius Z Anal Chem 216:94

22. Neeb R (1966) Fresenius $Z$ Anal Chem 222:290

23. Neeb R (1962) Fresenius Z Anal Chem 186:53

24. Bond AM (1980) Modern polarographic methods in analytical chemistry. Dekker, New York, p 361

25. Neeb R (1959) Fresenius Z Anal Chem 159:401

26. Neeb R, Saur D (1966) Fresenius Z Anal Chem 222:200

27. Willems G, Neeb R (1969) J Electroanal Chem 21:69

28. Neeb R (1969) Inverse Polarographie und Voltammetrie. Weinheim, Verlag Chemie

29. Henze G, Neeb R (1986) Elektrochemische Analytik. Springer, Berlin

30. Schaller H, Neeb R (1987) Fresenius Z Anal Chem 327:170

${ }^{1}$ Rolf Neebs Schriften. I am very thankful to D. Saur for giving me access to that book. 